\title{
AN EXPLORATORY STUDY OF THE MAIN BARRIERS TO LEAN CONSTRUCTION IMPLEMENTATION IN PERU
}

\author{
Cristian Huaman-Orosco ${ }^{1}$ and Andrews A. Erazo-Rondinel ${ }^{2}$
}

\begin{abstract}
Lean Construction (LC) has been implemented for 20 years in Peru in different types of projects: buildings, sanitary works, mining, sports infrastructure, and for the development of people, finding significant benefits after its implementation. However, some barriers make complicated Lean Construction from being applied in many projects in Peru. This research aims to identify and classify the obstacles that lead to poor implementation of Lean thinking. First, the study started with a literature review and consultation with six experts with more than ten years of experience in the implementation of Lean Construction in different types of projects, identifying thirty-two barriers to Lean Construction implementation, dividing the barriers into four types: culture barriers, technology barriers, lean philosophy, and other barriers. One hundred and twenty-four engineers from various projects are surveyed, and the main obstacles to Lean Construction implementation are ranked. The findings identified that "lack of government policies," "lack of alliances between academy and organizations," and "high use of time and cost with no return" are the main barriers related to the implementation of Lean. Research is the basis for generating a roadmap and lines of research.
\end{abstract}

\section{KEYWORDS}

Lean construction, challenges, barriers, Peru, Latin America.

\section{INTRODUCTION}

Lean Construction has been implementing since 2000 in Peru, with the book "Productivity in construction works" (Ghio, 2001). In this book, Ghio (2001) developed a study of productivity in Peru, and he identified the barriers that generate low productivity in the Peruvian construction sector. This book has served as a reference for various professionals to apply LC in different types of projects in Peru: mining projects (Izquierdo \& Arbulú, 2008 y Rosas et al. 2011), buildings (Murguia et al. 2016 y Lazarte, 2020), roads (Cabrera \& Li, 2014), sporting infrastructure (Erazo et al. 2020 y ErazoRondinel et al. 2020), sanitary works (Flores \& Ollero, 2013 and Yoza, 2011); This is how Peru, appears in the 14th position with 19 papers published in the IGLC (Engebø et al. 2017). However, lean implementation has focused heavily on tools such as the Last Planner System. (Murguia 2019), generating that people start using them without really

1 Graduate Student, Faculty of Civil Engineering, Universidad Nacional de Ingeniería, Lima, Peru, chuamano@uni.pe, orcid.org/0000-0002-8125-3768

2 Teaching Assistant, Faculty of Civil Engineering, Universidad Nacional de Ingeniería, Lima, Peru, aerazor@uni.pe, orcid.org/0000-0002-5639-573X 
understanding the benefits and purpose of Lean thinking. (Almanei et al., 2017); time and cost resources invested in implementation and continue to have problems of poor team coordination, unaligned objectives among project stakeholders, and unreliable planning.

Thus, the following study aims to identify the main barriers that make Lean Construction challenging to implement in Peru. First, a literature review of LC implementation barriers is conducted and validated with the judge experts with more than ten years of experience in LC implementation. After this, we surveyed professionals with 0 to 20 years of experience and with different roles in the industry (planning engineers, field engineers, project managers, technical office engineers, among others); with the data obtained from the surveys, we proceeded to identify the main barriers to LC implementation in Peru. The contribution of the research allows the involvement of the state, universities, and companies to disseminate its implementation in as many projects as possible, help professionals to highlight the barriers, and generate a roadmap to guide organizations.

\section{LITERATURE REVIEW}

Lean Construction is everyone's participation in the organization to identify waste and make minor incremental improvements daily, moving everyone in the same direction with common goals. Salvatierra et al. (2015) argue that implementing LC in an organization over the long term requires that people in the organization focus on Philosophy (All must understand lean principles, waste, and customer value). A culture generates social interaction among team members to engage them and adopt the philosophy to the project's complexities and technology that permits apply the philosophy through tools in an iterative process of continuous learning.

The partial or erroneous implementation of Lean Construction results in poor project management, poor coordination with the teams, and unreliable planning, affecting the trust between management and project workers. (Loosemore 2014). Most organizations start by implementing LC using part of the principles or tools (Soren 2014), generating that people implement LC without understanding the philosophy. Also, other organizations suffer in the implementation of LC due to the complexities and many participants in construction projects. These factors lower expectations and are perceived as high use of resources, cost, and time, returning to traditional systems (Okere 2017).

The most recurrent barriers that practitioners face when implementing lean could be indicated as inadequate training of practitioners, lack of top management leadership, long-term LC implementation planning, and people's resistance to change. Alarcón et al. (2002) refer that the full support of top management is required and that the information is available at all levels of the organization. Salvatierra et al. (2015) claim that implementing LC in the short term in temporary projects generates new problems. From the literature, barriers related to people, business, and education are observed. However, little is known about the specific factors that hinder LC deployment in Peru. Also, there is little knowledge about the impact of company size and sector on LC implementation. Understanding these factors would help engineers make better decisions when implementing LC in their projects or organization.

\section{LEAN IMPLEMENTATION BARRIERS}

Based on the Literature Review, we identified and classified barriers using the triangle of sustainable Lean practices (Salvatierra et al., 2015). The barriers identified are classified in table 1. 
Table 1: Barriers associated with the lean implementation.

\begin{tabular}{|c|c|}
\hline Variable & Reference \\
\hline \multicolumn{2}{|c|}{ Barriers associated with the Lean philosophy } \\
\hline $\begin{array}{l}\text { Lack of understanding of the fundamental purpose and rationale } \\
\text { for Lean implementation. }\end{array}$ & (Walter et al. 2020) \\
\hline $\begin{array}{l}\text { Lack of transparent information between team members and } \\
\text { management, reducing reliability in Lean. }\end{array}$ & (Liu et al. 2020) \\
\hline Local and not global flow optimization & (Almanei et al. 2017) \\
\hline $\begin{array}{l}\text { Lack of information exchange between teams, suppliers, } \\
\text { subcontractors, etc. }\end{array}$ & $\begin{array}{l}\text { (Demirkesen et al. } \\
\text { 2019) }\end{array}$ \\
\hline $\begin{array}{l}\text { Lack of long-term thinking in the organization for Lean } \\
\text { implementation }\end{array}$ & $\begin{array}{l}\text { (Shang y Sui Pheng } \\
\text { 2014) }\end{array}$ \\
\hline $\begin{array}{l}\text { Lack of clear definition of scope, identifying value and definition } \\
\text { from the customer's point of view. }\end{array}$ & (Sarhan y Fox 2012) \\
\hline Long duration of the Lean learning curve & (Almanei et al. 2017) \\
\hline Lack of leadership and empowerment of people in the project. & (Alarcón et al. 2005) \\
\hline \multicolumn{2}{|l|}{ Barriers associated with the lean culture } \\
\hline $\begin{array}{l}\text { Lack of centralized, stored, and shared information to generate a } \\
\text { continuous improvement cycle. }\end{array}$ & (Alarcón et al. 2005a) \\
\hline Incorrect selection of Lean tools & (Albliwi et al. 2014) \\
\hline $\begin{array}{l}\text { Ease of communication from top management with improvement } \\
\text { initiatives. }\end{array}$ & (Almanei et al. 2017) \\
\hline Resistance to change of people in the organization & (Murguia 2019) \\
\hline \multicolumn{2}{|l|}{ Barriers associated whit the lean tools } \\
\hline $\begin{array}{c}\text { Lack of self-criticism to learn from mistakes and identify } \\
\text { problems }\end{array}$ & (Alarcón et al. 2005) \\
\hline Lack of improvement culture throughout the organization & (Walter et al. 2020) \\
\hline Inability to measure team performance and progress & (Omran y Abdulrahim 2015) \\
\hline $\begin{array}{l}\text { Lack of advance work planning and realistic scheduling using } \\
\text { Lean tools }\end{array}$ & $\begin{array}{l}\text { (Cano et al. 2015; Murguia } \\
\text { 2019) }\end{array}$ \\
\hline Lack of time to implement Lean in ongoing projects & (Soto 2016) \\
\hline $\begin{array}{c}\text { Lack of collaboration of all project stakeholders at all levels and } \\
\text { early stages of design and production (suppliers, } \\
\text { subcontractors, etc.). }\end{array}$ & (Shang y Sui Pheng 2014) \\
\hline $\begin{array}{l}\text { People use tools without supporting them with culture and } \\
\text { philosophy. }\end{array}$ & (Salvatierra et al. 2015) \\
\hline \multicolumn{2}{|l|}{ Other barriers related to lean implementation. } \\
\hline Replicating the Lean strategy of another organization & (Albliwi et al. 2014) \\
\hline Lack of top management commitment to the implementation & (Demirkesen et al. 2019) \\
\hline Lack of knowledge and experience of implementers & (Soren 2014) \\
\hline $\begin{array}{l}\text { Lack of collaborative work between academia and the } \\
\text { construction industry }\end{array}$ & (Tsao et al. 2012) \\
\hline High cost of implementation & (Bashir et al. 2015) \\
\hline
\end{tabular}




\section{RESEARCH METHOD}

To better understand the study phenomenon, the authors conducted a literature review of Lean implementation barriers, followed by expert feedback and validation. The mixedmethod was used to take a "snapshot" of the study phenomenon (Cresswell, 2014), integrating qualitative and quantitative questions. Research starts with a literature review; later Lean Experts are selected for exploratory interviews and validation of the barriers. Finally, the mass survey is taken (See Figure 1).

Figure 1. Research methodology.

\section{LEAN EXPERTS SELECTION}

Nine expert professionals are targeted to be part of the research to align the objectives of the study; only six experts are selected based on the following characteristics:

- Civil Engineer with more than twelve years of experience implementing lean.

- Professionals with teaching experience, published articles and at least a master's degree.

The interview with the experts are based on general and structured interviews; the following results are obtained in the three stages of the interview:

Table 2: Expert interview results.

\begin{tabular}{|c|c|c|}
\hline Stage & Structure & Results \\
\hline 1 & $\begin{array}{l}\text { General data, } \\
\text { experience in its } \\
\text { implementation, } \\
\text { results obtained in its } \\
\text { implementation and } \\
\text { difficulties. }\end{array}$ & $\begin{array}{l}\text { Served as a criterion for the selection of the expert. } \\
\text { To know the expert's profile. } \\
\text { Preliminary overview of the study phenomenon and } \\
\text { alignment of the study goal. }\end{array}$ \\
\hline II & $\begin{array}{l}\text { Questions related to } \\
\text { the type of project for } \\
\text { each expert. } \\
\text { Preliminary review of } \\
\text { barriers according to } \\
\text { literature references. }\end{array}$ & $\begin{array}{l}\text { Emphasis on barriers according to the type of project. } \\
\text { Readjustment of the negative syntax to positive or neutral, } \\
\text { to avoid influencing and sympathizing with the respondent. } \\
\text { Priority was given to } 32 \text { barriers out of } 78 \text { identified in the } \\
\text { literature. }\end{array}$ \\
\hline III & $\begin{array}{l}\text { Review of questions to } \\
\text { achieve objectives. } \\
\text { Validation of barriers } \\
\text { through the experience } \\
\text { of each expert. }\end{array}$ & $\begin{array}{l}\text { Final survey. } \\
\text { Identification of patterns of barriers and the study } \\
\text { population. }\end{array}$ \\
\hline
\end{tabular}

After stage two, the experts identied the next new barriers: (1) Contracts do not require the use of Lean, leaving it to the company's choice. (2)Low capacity of people to recognize waste. (3) Lack of government policies to incentivize the use of Lean. (4) People in meetings do not respect the opinion of others and impose their ideas. (5) The 
low empowered capacity of people in the organization delays decision making. (6) Low organizational commitment. (7) Do you agree that universities provide sufficient lean training to perform in the labor market.

\section{SAMPling, Profile and Respondent Ethics}

In this study, accidental non-probability sampling has been performed based on the researchers' knowledge, experts, and the study objectives. The characteristics of the respondents are Peruvian civil engineers with at least two years of experience working under the Lean philosophy or participating in a project implemented with Lean. Ethical issues were related to the confidentiality and data protection of the survey. Respondents are aware that they could leave the questionnaire at any time.

\section{InSTRUMents, Data Sizes ANd Data ANAlysis}

The survey followed a cross-sectional process to get the most important data and ease of remote response. The questionnaire had 40 open-ended and closed-ended questions. The research team disseminated the survey to Lean organizations, companies, and professionals involved in LC practices through e-mails, social networks, and professional networks. After that, the team sent a total of 1300 mailings. One hundred seventy-four participants complete the survey; 50 are discarded for not meeting the study profile, abandoned surveys, or anomalous data correlation between themselves or about the mean. Barriers are evaluated using a Likert scale of 1 to 5 points, asking respondents to rate which variables they most frequently experienced in their project and are evaluated as "Never=1, Rarely=2, Occasionally=3, Frequently=4 and Very frequently=5". For example, how often does the project team experience reflections on activities carried out and suggestions for good practices? The respondent can choose to rate on a scale of 1 to 5. Thus, the more frequently used, the more common practice among professionals and the less frequently used the practices become barriers that prevent the development of the implementation. The average frequency of use is used to prioritize barriers, where the lower the numerical value, the higher the priority as a barrier. Quantitative data were analyzed and represented with descriptive statistics. The qualitative data served to confirm, corroborate, and have explanations of the barriers. After that, the integration of both data allowed for a better analysis of the study.

\section{JUSTIFICATION OF THE METHOD}

The mixed-method is used to have a better understanding of the phenomenon. The mixed method allows a greater variety of perspectives on frequency, generality, complexity, size, and comprehension of the problem. Quantitative to identify the company's size, years of experience, frequency of use of best practices. Qualitative to describe their experiences, personal difficulties, or experiences. Integrating both methods allowed the questionnaire to be improved by the experts. After the pilot plan, new questions are identified and readjusted thanks to the corroboration of qualitative and quantitative data. Nonprobabilistic and accidental sampling is used to get as much data as possible conditioned to the study's objectives.

\section{RESULTS AND DISCUSSION}

Experts validated the questionnaire and the consistency of 0.95 or $5 \%$ error with Cronbach's Alpha $(\alpha)$. Table 3 shows the relevant results of the 124 respondents. 
Table 3. Bibliographic characteristics of the survey respondents.

\begin{tabular}{|c|c|c|}
\hline Demographic characteristics & Frequency & Percentage \\
\hline \multicolumn{3}{|l|}{ Experience } \\
\hline $1-5$ years & 82 & $66.39 \%$ \\
\hline $6-10$ years & 24 & $19.33 \%$ \\
\hline $11-15$ years & 10 & $7.56 \%$ \\
\hline 16-20 years & 6 & $5.04 \%$ \\
\hline More than 20 years & 2 & $1.68 \%$ \\
\hline \multicolumn{3}{|l|}{ Experience working with lean. } \\
\hline $1-2$ years & 51 & $41.13 \%$ \\
\hline $3-5$ years & 38 & $30.65 \%$ \\
\hline $6-8$ years & 21 & $16.94 \%$ \\
\hline 9- 10 years & 12 & $9.68 \%$ \\
\hline More than 10 years & 2 & $1.61 \%$ \\
\hline \multicolumn{3}{|l|}{ Organization } \\
\hline Construction & 92 & $73.95 \%$ \\
\hline Consulting and project supervision & 9 & $7.56 \%$ \\
\hline Project formulation and design & 8 & $6.72 \%$ \\
\hline Project logistics and maintenance & 4 & $2.52 \%$ \\
\hline suppliers & 2 & $1.68 \%$ \\
\hline other & 9 & $7.56 \%$ \\
\hline \multicolumn{3}{|l|}{ Project Type } \\
\hline Buildings & 59 & $47.5 \%$ \\
\hline Infrastructure & 37 & $30 \%$ \\
\hline Industrial plants & 7 & $5 \%$ \\
\hline Energy and oil & 6 & $4.17 \%$ \\
\hline Other & 15 & $11.67 \%$ \\
\hline \multicolumn{3}{|l|}{ Size of organization } \\
\hline micro (1 to 10 people) & 27 & $22 \%$ \\
\hline small (10 to 50 people) & 32 & $26 \%$ \\
\hline medium (50 to 250 people) & 30 & $24 \%$ \\
\hline Large (more than 250 people) & 35 & $28 \%$ \\
\hline
\end{tabular}

The main barriers identified are related to the group of other factors and philosophy. The other group is related to policy factors and the public project management system. The understanding of the philosophy is still difficult. Using descriptive statistics, Table 4 shows that "Lack of government policies to encourage the use of Lean" and "Lack of collaborative work between academia and the construction industry" are the most significant barriers. It can be determined that the government and academia play a significant role in generating a Lean system, where builders, designers, suppliers, and subcontractors are quickly integrated into Lean practices. "High cost of implementation" shows that practitioners identify that it requires a high degree of time and financial resources, especially time. "Low empowered capacity of people in the organization delays decision making," "Low knowledge of Lean among university graduates" indicate that professionals have low knowledge of Lean, making it difficult for them to empower themselves and lead Lean implementation. "Lack of top management commitment to 
implementation" and "Long duration of the Lean learning curve" show that companies do not have top management leadership and do not have labor insertion policies to generate gradual knowledge in Lean implementation. "Lack of knowledge of the fundamental purpose and rationale for Lean implementation" shows that it is still complex for people to understand Lean due to the low number of resources in the language and local studies on the benefits of Lean. "Contracts do not require the use of Lean, leaving it to the company's choice" and "Lack of time to implement Lean in ongoing projects" show that clients are unaware of the benefits of applying Lean in their project and require their builders to use it.

Table 4: Most important barriers to Lean Construction implementation

\begin{tabular}{|c|c|c|c|}
\hline Variable & s.d. & Mean & Rank \\
\hline Lack of government policies to encourage the use of Lean. & 1.71 & 2.51 & 1 \\
\hline $\begin{array}{l}\text { Lack of collaborative work between academia and the } \\
\text { construction industry. }\end{array}$ & 1.39 & 2.57 & 2 \\
\hline High cost of implementation & 1.02 & 2.74 & 3 \\
\hline $\begin{array}{l}\text { Low empowered capacity of people in the organization } \\
\text { delays decision making. }\end{array}$ & 0.84 & 2.95 & 4 \\
\hline Low knowledge of Lean among university graduates. & 0.89 & 2.95 & 5 \\
\hline Lack of top management commitment to implementation & 1.38 & 3.04 & 6 \\
\hline Long duration of the Lean learning curve & 1.15 & 3.04 & 7 \\
\hline $\begin{array}{l}\text { Lack of knowledge of the fundamental purpose and rationale } \\
\text { for Lean implementation }\end{array}$ & 0.86 & 3.17 & 8 \\
\hline $\begin{array}{l}\text { Contracts do not require the use of Lean, leaving it to the } \\
\text { company's choice. }\end{array}$ & 1.57 & 3.18 & 9 \\
\hline Lack of time to implement Lean in ongoing projects & 1.41 & 3.21 & 10 \\
\hline
\end{tabular}

The study results show that the lack of government policies to incentivize the use of Lean, many authors consider this as an important barrier (Cano et al., 2015; Demirkesen et al., 2019). Lack of government policies demonstrates the importance of the government to generate lean practitioner environments to engage and empower their organization as the final customer, and the government can demand organizations due to significant investments in public projects. The government needs to change, update, and adapt its project bidding policies to break its traditional project management. The little interaction between academia and industry is corroborated by the few courses dictated on LC in universities, and this point was also mentioned by (Ghio 2001; Tsao 2012). The government and academia oversee disseminating, educating, and training professionals to generate a Lean environment; academy and organization alliances could help solve problems, generate more academic resources in research and create a career line for those involved. The "high resource costs in implementation" are related to the fact that a lot of time effort is required to train project people and a cost with no return due to the temporality of the project; this finding is related to Almanei et al. (2017). This barrier is generated because practitioners still do not understand the benefits of Lean in the long term and focus to a greater extent on the short term. Finally, the "lack of knowledge of Lean in the qualified professionals" is a barrier many implementers agree (Cano et al., 2015; Demirkesen et al., 2019; Walter et al. 2020). Overcoming this barrier will allow the spread of Lean and reduce the impact of other barriers such as: "resistance to change," 
"the perception of the high cost of implementation," "top management does not support the changes," and others. Lean implementation is not directly related to concepts or techniques but business processes. The implementation must be done at the enterprise level, but it requires management and managing the learning curve.

\section{CONCLUSIONS}

Implementing Lean in Peru may be relatively new to many. The study focuses on identifying the main barriers to successful Lean implementation. The information gathered from implementers and the literature reviews used in the study show that the main barriers are: "Lack of government policies," "Lack of collaborative work between academia and business," "High cost of implementation," and "Lack of knowledge of lean in professionals graduated from universities." The barriers identified in the literature review in international research are not reflected in Peru; so, specific barriers are depending on the geographical location, the political context, and the type of industry. Peruvian professionals show a low level of awareness and knowledge about lean. These results evidence the need to focus more on philosophy and technology. It may be easier to start lean implementation by private companies rather than public companies. Finally, understanding, adapting, implementing, and disseminating Lean in Peru requires much effort by all professionals and the commitment of the State, universities, and companies. This study is the basis for proposing a lean implementation roadmap to reduce these barriers.

\section{REFERENCES}

Alarcón, L., Diethelm, S., Rojo, O., y Calderon, R. (2005). “Assessing the Impacts of Implementing Lean Construction". Proc. 13th International Group for Lean Construction Conference, Sydney, Australia.

Alarcón, L. F., Diethelm, S., y Rojo, Ó. (2002). "Collaborative Implementation of Lean Planning Systems in Chilean Construction Companies". 10th Annual Conference of the International Group for Lean Construction, Gramado, Brazil.

Albliwi, S., Antony, J., Lim, S. A. H., y van der Wiele, T. (2014). "Critical failure factors of lean Six Sigma: A systematic literature review". International Journal of Quality and Reliability Management, 31(9), 1012-1030.

Almanei, M., Salonitis, K., y Xu, Y. (2017). "Lean Implementation Frameworks: The Challenges for SMEs". Procedia CIRP, The Author(s), 63, 750-755.

Arbulu, R., y Zabelle, T. (2006). "Implementing Lean in Construction: How to Succeed". Proc. 14th Annual Conference of the International Group for Lean Construction, Santiago, Chile.

Bashir, A., Suresh, S., Oloke, D., Proverbs, D., y Gameson, R. (2015). "Overcoming the Challenges facing Lean Construction Practice in the UK Contracting Organizations". International Journal of Architecture, Engineering and Construction.

Cresswell, J.W., (2014). Research Design. Qualitative, Quantitative and Mixed methods approach 4th ed., London: Sage.

Cano, S., Delgado, J., Botero, L., y Rubiano, O. (2015). "Barriers and Success Factors in Lean Construction Implementation Survey in Pilot Contex". Proc. 23rd Annual Conference of the International Group for Lean Construction, Perth, Australia.

Demirkesen, S., Wachter, N., Oprach, S., y Haghsheno, S. (2019). "Identifying Barriers in Lean Implementation in the Construction Industry". Proc. 27th Annual Conference of the International Group for Lean Construction, Dublin, Ireland. 
Engebø, A., Drevland, F., Lohne, J., Shkmot, N., y Lædre, O. (2017). “Geographical Distribution of Interest and Publications of Lean Construction". Proc. 25th Annual Conference of the International Group for Lean Construction, Heraklion, Greece.

Erazo-Rondinel, A. A., Vila-Comun, A., y Alva, A. (2020). "Application of the Last Planner ${ }^{\circledR}$ System in a Sports Infrastructure Project in Perú". Proc. 28th Annual Conference of the International Group for Lean Construction, Berkeley, California.

Erazo, A., Guzman, G., y Espinoza, S. (2020). "Applying BIM Tools in IPD Project in Perú". Proc. 28th Annual Conference of the International Group for Lean Construction, Berkeley, California.

Flores, G., y Ollero, C. (2013). "Productivity Improvement Applying Production Management in Projects with Repetitive Activities". Proc. 21st Annual Conference of the International Group for Lean Construction, Fortaleza, Brazil.

Forero, S., Cardenas, S., Vargas, H., y Garcia, C. (2015). "A Deeper Look Into the Perception and Disposition to Integrated Project Delivery (IPD) in Colombia". Proc. 23rd Annual Conference of the International Group for Lean Construction, Perth, Australia.

Ghio, V. (2001). Construction Site Productivity. Pontificia Universidad Católica del Perú, Lima.

Gutiérrez, F. M. (2020). "Influence of Integrated Teams and Co-Location to Achieve the Target Cost in Building Projects". Proc. 28th Annual Conference of the International Group for Lean Construction, Berkeley, California.

Izquierdo, J. L., y Arbulu, R. (2008). "Application of Production Management in Industrial EPC and Mining Projects in Peru". Proc. 16th Annual Conference of the International Group for Lean Construction, Manchester, UK.

Liu, C., González, V. A., Liu, J., Rybkowski, Z., Schöttle, A., Mourgues Álvarez, C., y Pavez, I. (2020). "Accelerating the Last Planner System ${ }^{\circledR}$ (LPS) Uptake Using Virtual Reality and Serious Games: A Sociotechnical Conceptual Framework". Proc. 28th Annual Conference of the International Group for Lean Construction, Berkeley, California.

Loosemore, M. (2014). "Improving Construction Productivity: A Subcontractor's Perspective". Engineering, Construction and Architectural Management, 21(3), 245260.

Murguia, D. (2019). "Factors Influencing the Use of Last Planner System Methods: An Empirical Study in Peru". Proc. 27th Annual Conference of the International Group for Lean Construction, Dublin, Ireland.

Murguía, D., Brioso, X., y Pimentel, A. (2016). “Applying Lean Techniques to Improve Performance in the Finishing Phase of a Residential Building”. Proc. 24th Annual Conference of the International Group for Lean Construction, Massachusetts, USA.

Okere, G. (2017). "Barriers and Enablers of Effective Knowledge Management: A Case in the Construction Sector". The Electronic Journal of Knowledge Management, 15(2), 85-97.

Omran, A., y Abdulrahim, A. (2015). "Barriers to prioritizing lean construction in the Libyan Construction Industry". Acta Tehnica Corviniensis, (1998), 1-4.

Román, B., y Juárez, G. (2014). “A Lean-Triz Approach for Improving the Perfomance of Construction Projects”. Proc. 22nd Annual Conference of the International Group for Lean Construction, Oslo, Norway. 
Rosas, E., Ríos, L., y Carrera, D. (2011). "Implementing Last Planner in Open Pit Mining Projects: Case Study". Proc. 19th Annual Conference of the International Group for Lean Construction, Lima, Peru.

Salvatierra, J. L., López, A., Alarcon, L. F., y Velásquez, X. (2015). "Lean Diagnosis for Chilean Construction Industry: Towards More Sustainable Lean Practices and Tools". Proc. 23rd Annual Conference of the Internatioanl Group for Lean Construction, Perth, Australia.

Sarhan, S., y Fox, A. (2012). "Trends and Challenges to the Development of a Lean Culture Among UK Construction Organisations". Proc. 20th Annual Conference of the International Group for Lean Construction, San Diego, California.

Shang, G., y Sui Pheng, L. (2014). "Barriers to Lean Implementation in the Construction Industry in China". Journal of Technology Management in China, 9(2), 155-173.

Soren, W. (2014). "Lean Construction With or Without Lean Challenges of Implementing". Proc. 22th Annual Conference of the International Group for Lean Construction, Oslo, Norway.

Soto, U. (2016). "Maturity Assessment of Lean Principles in Construction Projects". Pontificia Universidad Católica de Chile.

Tsao, C., Alves, T., y Mitropoulos, P. (2012). "Different Perspectives on Teaching Lean Construction". Proc. 20th Annual Conference of the International Group for Lean Construction, San Diego, California.

Walter, R., Weinmann, M., Baier, C., Oprach, S., y Haghsheno, S. (2020). "A Requirement Model for Lean Leadership in Construction Projects". Proc. 28th Annual Conference of the International Group for Lean Construction, Berkeley, California.

Yoza, A. (2011). "Impact of 'The last planner' Method on Sanitation works". Proc. 19th Annual Conference of the International Group for Lean Construction, Lima, Peru. 